Zhong, L. (2017). The Effectiveness of K-12 Principal's Digital Leadership in Supporting and Promoting Communication and Collaboration Regarding CCSS Implementation. Journal of Educational Technology

\title{
The Effectiveness of K-12 Principal's Digital Leadership in Supporting and Promoting Communication and Collaboration Regarding CCSS Implementation
}

\author{
Lin Zhong \\ Southern Illinois University
}

\begin{abstract}
Technology plays an important role in supporting successful College-and CareerState Standards (CCSS) implementation, which requires principals and educators effectively communicate and collaborate at the local, state, and national level. This study aims to investigate the effectiveness of digital leadership in supporting communication and collaboration regarding CCSS implementation in K-12 schools. In this study, 254 public school teachers from five school districts in Mississippi were surveyed. Results showed that principals were most effective in supporting professional development and digital citizenship. In addition, teachers' age and teaching grades have an impact on the effectiveness of principals' digital leadership strategies. Implications are discussed in the final section.
\end{abstract}

Keywords: digital leadership, CCSS, communication, collaboration, K-12, ISTE-A

\section{Introduction}

Common Core State Standards (CCSS) are high-quality national academic requirements in English Language Arts or Literacy (ELA) and Mathematics. Principals play an essential role in leading educational reform such as CCSS (Creighton, 2003). Principals directly affect how CCSS is perceived by teachers, students, and parents. In addition, principals' modeling strategies have an effect on CCSS implementation (Marks, 2003).

However, without the aid of technology, implementing CCSS is a challenge for principals. Nowadays, everything is becoming digitally. Digital tools and resources have expanded extensively. The ways of leading schools have switched from traditional face-to-face administration to digital leadership. Technology is an embedded part of education and administration, such as communicating and collaborating digitally. Effective communication and collaboration are the keys to successful educational reform (Blase \& Blase, 2000). Clear communication decreases misunderstanding and increases productivity. For principals, establishing the school environment characterized by effective communication and collaboration 
has a significant influence on successful CCSS implementation. Therefore, researching how to support communication and collaboration has practical significance in leading CCSS successfully.

Although how to use technologies to support effective communication and collaboration has been heavily researched, few studies have investigated how K-12 principals use digital technology to support effective communication and collaboration so that schools can successfully implement CCSS. The main purpose of this study is to investigate the effectiveness of K-12 principal's digital leadership in supporting communication and collaboration regarding CCSS implementation. The structure of this article is as follows. First, digital leadership and CCSS are reviewed to provide theoretical backgrounds for this study. Three research questions were presented in this section to guide this study. Second, research method, including setting, participants, data collection, and data analysis, was discussed with more details. The third and fourth sections provide results and discussion of this study. The final section concludes this article with implications and recommendations for future research.

\section{Literature Review}

\subsection{Digital leadership}

Digital leadership that bridged two fields of leadership and instructional technology was also termed by other researchers as educational technology leadership (Kearsley \& Lynch, 1994), information and communication technology (ICT) leadership (Afshari, Bakar, Luan, \& Siraj, 2012), technology leadership (Arokiasamy, Abdullah \& Ismail, 2014), and e-leadership (Jameson, 2013). In 2009, International Society for Technology in Education (ISTE) updated National
Educational Technology Standards (NETS) for Administrators (NETS-A) standards, renamed as International Society for Technology in Education for Administrators (ISTE-A), to help education leaders better prepare for leadership practice in the fast-developing digital world. ISTE-A standards discuss digital leadership from five perspectives: visionary leadership, digital age learning culture, excellence in professional development, systemic improvement, and digital citizenship. In other words, according to ISTE-A standards, digital leadership contains five scales: visionary leadership, digital age learning culture, excellence in professional development, systemic improvement, and digital citizenship (ISTE, 2009). Visionary leadership refers to inspiring and leading "development and implementation of a shared vision for comprehensive integration of technology to promote excellence and support transformation throughout the organization" (ISTE, 2009). Digital age learning culture is defined as creating, promoting, and sustaining "a dynamic, digital-age learning culture that provides a rigorous, relevant, and engaging education for all students" (ISTE, 2009). Excellence in professional development is defined as promoting "an environment of professional learning and innovation that empowers educators to enhance student learning through the infusion of contemporary technologies and digital resources" (ISTE, 2009). Systemic improvement is defined as providing "digital age leadership and management to continuously improve the organization through the effective use of information and technology resources" (ISTE, 2009). Digital citizenship is defined as modeling and facilitating "understanding of social, ethical and legal issues and responsibilities related to an evolving digital culture" (ISTE, 2009).

ISTE-A standards have been published for several years and play an essential role 
The Effectiveness of K-12 Principal's Digital Leadership in Supporting and Promoting Communication and Collaboration Regarding CCSS Implementation

in understanding and evaluating digital leadership. Educators utilized ISTE-A standards as a framework and performance indicators to decide what technology skills administrators should possess and how to evaluate administrators' digital leadership skills (Cakir, 2009; Dickerson, Winslow, Lee, \& Geer, 2011; Garcia \& Abrego, 2014; Newton, da Costa, Peters, \& Montgomerie, 2011; Rivard, 2010; Winslow, Dickerson, Lee, \& Geer, 2012; Zhong, 2017). Among numerous studies of ISTE-A, researchers not only took use of ISTE-A standards as tools to address and evaluate digital leadership skills (McLeod \& Richardson, 2013), but also went further to discuss each indicator of digital leadership addressed by ISTE-A standards (Afshari et al., 2010; Butler, 2010; Dessoff, 2010; Lecklider, Clausen, \& Britten, 2009; McCombs, 2010; Ribble \& Miller, 2013; Richardson, Flora, \& Bathon, 2013; Yang \& Chen, 2010). Darrow (2010) described how administrators worked together with students, teachers, and stakeholders to create a shared vision on online programs. Lecklider et al. (2009) provided an example of creating a digital learning culture to promote education innovation. Results emphasized that professional development was the first priority indicator compared with others. Banoglu (2011) adapted ISTA-A evaluation survey (PTLA) and examined principals' digital leadership competency. Further comparison and discussion of each dimension of the ISTA-A standards were also conducted in the study. Statistical results showed that visionary leadership had the lowest value compared with other indicators. Results revealed that gender had an effect on the technology vision because female principals possessed stronger communication and collaboration skills to build a shared visionary leadership with other educators. Additionally, technological resource, such as the technology coordinator, was reported as the leading contributor of principals' technology proficiency because of technology coordinators' encouragement of technological innovation.

The conclusion was evidently consistent with Metcalf and LaFrance's research (2013). Metcalf and LaFrance (2013) measured technology leadership preparedness from principals' perception guided by the five themes of ISTE-A standards. Results revealed that digital citizenship was the most prepared indicator while visionary leadership was the least prepared indicator. Metcalf and LaFrance (2013) agreed that ISTE-A standards should be aligned and incorporated with principal preparation programs as well as district supplemental programs. Curnyn (2013) asserted that visionary leaders should lead and consider the influence of the emerging technology on learning and teaching. Visionary leaders should seek and promote communication and collaboration. Larson, Miller, and Ribble (2009) suggested five considerations regarding the five standards of ISTE-A standards. Larson et al. (2009) asserted that a proactive technology plan includes a creative and innovative classroom environment, use of a systems perspective, a consistent professional development plan, and an assessment of appropriate technology use. Garciaand Abrego (2014) interviewed five principals and surveyed 67 in-service elementary principals to explore fundamental skills of digital leadership. Four themes aligned with ISTA-A standards were summarized as fundamental skills of digital leadership: the familiarity with software and hardware, using information and data retrieval, communicating with stakeholders, and planning and management of resources. Wang (2010) discussed all sections of ISTE-A standards with situational contexts and specific activities and tasks. Guiding questions, which were useful for school leaders, were provided after each discussion section. Richardson 
et al. (2012) reviewed the studies published from 1997 to 2010 to investigate how each performance indicator of digital leadership was studied in the field. Results showed that systemic improvement and digital citizenship were paid less attention and more studies were needed for the two indicators. They suggested that in-depth research could help school leaders face the challenges of implementing digital transformation in schools. Unfortunately, Richardson et al.'s (2012) study did not discuss the possible relationship that existed among indicators, even though results revealed the existence of the relationship. Results in the systemic improvement section showed that systemic improvement had a positive impact on digital learning culture (Lecklider et al., 2009). In addition, visionary leadership combined with systemic improvement had an effect on digital learning culture (Ritzhaupt, Hohlfeld, Barron, \& Kemker, 2008).

\subsection{Common Core State Standards (CCSS)}

Common Core State Standards (CCSS) are high-quality national academic requirements in English Language Arts or Literacy (ELA) and Mathematics. Two categories, including expectations for college and workforce after graduation and expectations for K-12 education, were incorporated into CCSS. CCSS was launched in 2009. CCSS clarifies what students need to know and be able to do after they finish learning at each grade level. The standards aim to prepare American students from kindergarten to 12 th grade ready for their two-year or four-year college or workforce career after graduation. CCSS aligns all K-12 students together at a national level so that students have equal education access regardless of their locations.

Technology is an important element of CCSS standards. The shifting role of technology requires educators to adjust teaching and learning to ensure successful CCSS implementation. The technology was no longer an option for teachers and students to choose. Instead, technology was embedded into CCSS and considered "an integral tool for learning as mighty as the pen" (Graham, 2013, p. 1) rather than a set of skills. McLaughlin and Overturf (2012) advocated using technology as an important way of improving learning effectiveness to meet CCSS standards. McLaughlin and Overturf (2013) further explained that technology helped educators plan learning activities, assess academic performance, and, more importantly, understand students' learning needs. Online learning space, such as Wordpress, was suggested as a good way of constructing the CCSS learning environment (McLaughlin \& Overturf, 2012). Abundant of resources and tools were available for educators to meet the requirements of CCSS standards. However, studies showed that technology is still an issue and teachers are struggling with CCSS even teachers showed positive attitudes towards CCSS (Burton, 2014; Cheng, 2012). The CCSS survey conducted by the Center on Education Policy (CEP) showed that technology was one of the major challenges in implementing CCSS. According to the survey, 20 states reported that the major challenge for them was to have enough computers and Internet in schools. In addition, providing adequate technological experts at state, district, and school levels was also a challenge for administrators (Kober \& Renter, 2012). Teachers expressed their needs of teaching strategies and resources in the classroom (Hipsher, 2014). Lack of communication and collaboration was considered as the explanation for the rising frustration and confusion (Hipsher, 2014), "Frustration stemmed from a lack of coordination of information" (p. 79). Different schools had different assessment approaches 
The Effectiveness of K-12 Principal's Digital Leadership in Supporting and Promoting Communication and Collaboration Regarding CCSS Implementation

and teachers were uncertain about what students were expected to do because of the conflicting information. Thus, to successfully implement CCSS, effective communication and collaboration were important and should not be ignored (Stegmaier, 2013; Vasinda, 2014).

Technology has been immediately identified as an effective tool of enhancing communication and collaboration to enhance CCSS implementation (Cogan, Schimidt, \& Houang, 2013; Gallia, 2013; Royer \& Richards, 2013; Yim, Warschauer, Zheng, \& Lawrence, 2014). Brandt (2012) emphasized that various media was pivotal to providing clear and consistent communication to all stakeholders. Creating online professional learning communities was reported as a good strategy for facilitating communication and collaboration (Underwood, 2014). This recommendation is also proved to be effective in Robertson's (2013) report. Robertson (2013) shared his experience of assisting a district with cloud-computing system application to communicate with more than 600 staff members and to provide ongoing professional development. Results showed that cloud-based computing system helps schools solve the problem of communication and provided a collaborative place that allowed teachers to develop and discuss instructional materials regarding CCSS. Zhang (2014) also recommended creating an online professional learning community so that teachers could share resources and discuss issues they encountered. Hipsher (2014) also advocated the incorporation of technology into professional development, educational learning communities development, and connection with all stakeholders. According to Tucker (2012), introducing technology enabled teachers to overcome their fears and barriers. Providing teachers with appropriate technological resources would support teachers' effort of integrating technology into teaching (Holliday \& Smith, 2012).

Review of the literature related to CCSS indicates that successful implementation of CCSS requires educators effectively communicate and collaborate at the local, state, and national levels. However, studies that explored how principals could support communication and collaboration through the use of technology to help CCSS transition are quite limited. Researching how principals support communication and collaboration through technology during CCSS implementation has a practical significance for principals and educators. The following questions are examined in this study:

1. Are digital leadership strategies effective in supporting and promoting communication and collaboration regarding CCSS implementation in Mississippi?

2. To what extent are digital leadership strategies effective in supporting and promoting communication and collaboration regarding CCSS implementation in Mississippi?

3. Do teachers' demographics make a difference in effectiveness of digital leadership?

\section{Method}

Non-experimental descriptive design is appropriate for this study because this study aims to examine the effectiveness of supporting communication and collaboration through technology and the research setting remains the same. Non-experimental design tested the variables without controlling the research conditions. Cross-sectional design, which was one of the basic types of descriptive design, was utilized to collect data 
because the data was collected on a single point time. Surveys were frequently used method to collect data within cross-sectional design (Rovai, Baker, \& Ponton, 2014).

\subsection{Research Setting}

The research settings are five public school districts with 59 public schools in Mississippi. All school districts have technology department, which aims to provide technical support for teachers, students, and staff. Classrooms have at least three desktops. All the libraries are equipped with computers connected to online learning resources. All buildings have access to Internet and mobile computer carts. All teachers are provided with laptops. After-school technology workshops are provided for teachers once a week. The after-school technology workshop participation was voluntary. Teachers can request technology assistance from the help desk of the district official website. Teachers' requests are delivered to different instructional specialists based on the request categories. Instructional specialists help teachers solve issues addressed at teachers' requests. Teachers' smartphones are also important communication tools. Text message is an important way of communication because teachers can get quick response. School announcements are made over email, school speaker, and other notification system. Monthly meetings are held during the last week of each month with the intent of providing opportunities for teachers to communicate and collaborate.

\subsection{Participants}

Participants were 254 public school teachers from the five school districts. Recruitment email was sent to all teachers in the five school districts. Convenience sampling, which is the most commonly used sampling method in social science research, is chosen as the sampling strategy for this study to ensure all people are included as research participants. Criteria for being included in the sample is that participants (a) have experience of working as K-12 teachers and (b) participate in CCSS implementation.

\subsection{Data Collection}

Survey was used to collect data in this study. The survey was developed by the author and Cronbach's Alpha was 0.79, which indicated reliability of the survey. The survey composes of six scales: (1) demographic information, (2) visionary leadership, (3) digital learning culture, (4) professional development, (5) systemic improvement, and (6) digital citizenship. The first scale was used to collect participants' demographic information, including gender, age, education level, and teaching experience. All other five scales consist of four statements that describe the principal' digital leadership strategies. Qualtrics research suite was utilized as the survey development and delivery tool. The survey link generated by Qualtrics was included in the recruitment email for participants. Once participants completed the survey, their responses, including spreadsheet, raw data, variable, and value labels, and fixed field text, were downloaded from Qualtrics for further analysis.

\subsection{Data Analysis}

One-way ANOVA and post-hoc Tukey's HSD were the data analysis methods. ANOVA was used to determine the statistical significance of the items in each scale and also find the statistical significance. After getting results of ANOVA, Tukey's HSD was conducted to identify the significantly different scale of digital leadership strategies and significantly different statement of each scale. 
The Effectiveness of K-12 Principal's Digital Leadership in Supporting and Promoting Communication and Collaboration Regarding CCSS Implementation

Bar chart was also generated for each scale of digital leadership.

According to Fowler (2014), data collected by a survey must be translated into an appropriate format that can be read and analyzed by computer. The process of translating survey data is called coding data (Fowler, 2014). Qualtrics can code survey responses automatically when the survey report is generated. Code of each response in this study is shown in Table 1. Internal consistency was first checked before data analysis. Cronbach's alpha was calculated to determine the reliability of the five scales. The average rating for each statement and each scale were calculated. By comparing the average score of each scale, the researcher determined the effectiveness of each scale and answered the research question 1 and 2 . MANOVA was then calculated to determine the impact of demographics on the scales of digital leadership, which indicated the answers to the research question 3 .

Table 1. Codebook of Survey

\begin{tabular}{|l|l|}
\hline Survey Answer & Code \\
\hline Female & 2 \\
\hline Male & 3 \\
\hline 20-25 years old & 1 \\
\hline 26-34 years old & 2 \\
\hline $35-54$ years old & 3 \\
\hline 55-64 years old & 4 \\
\hline 65 or above & 5 \\
\hline High School/GED & 1 \\
\hline Some College & 2 \\
\hline 2-year College Degree & 3 \\
\hline 4-year College Degree & 4 \\
\hline Masters' Degree & 5 \\
\hline Specialists' Degree & 6 \\
\hline Doctoral Degree & 7 \\
\hline Professional Degree (JD, MD) & 8 \\
\hline Kindergarten & 1 \\
\hline Elementary grade 1-4 & 2 \\
\hline Elementary grade 5-8 & 3 \\
\hline High School grade 9-12 & 4 \\
\hline Strongly Disagree & 1 \\
\hline Disagree & 2 \\
\hline Neither Agree nor Disagree & 3 \\
\hline Agree & 4 \\
\hline Strongly Agree & 5 \\
\hline
\end{tabular}




\section{Results}

Cronbach's Alpha was first calculated to determine the reliability of the sub-scales within the survey. Cronbach's Alpha is 0.79 $(>0.7)$, which means the survey is effective and results are reliable.

\subsection{Demographic information}

Raw data was downloaded directly from Qualtrics. Demographics are summarized in Table 2, Table 3, Table 4, and Table 5.

\subsection{Digital Leadership}

Table 6 showed the initial diagnostics statistics of each scale that describes digital leadership. According to Table 6, professional development has the highest rating. Digital citizenship has the second highest rating. Digital learning culture is in the third place. Visionary leadership has similar rating as systemic improvement.

Table 2. Gender of teachers

\begin{tabular}{|l|l|}
\hline Gender & Teacher Number \\
\hline Female & 210 \\
\hline Male & 44 \\
\hline
\end{tabular}

Table 3. Age of teachers

\begin{tabular}{|l|l|}
\hline Age & Teacher Number \\
\hline $20-25$ & 24 \\
\hline $26-34$ & 62 \\
\hline $35-54$ & 128 \\
\hline 55 & 37 \\
\hline 64 & 3 \\
\hline
\end{tabular}

Table 4. Education of participants

\begin{tabular}{|l|l|}
\hline Education & Teacher Number \\
\hline High School/GED & 1 \\
\hline Some College & 0 \\
\hline 2-year College Degree & 0 \\
\hline 4-year College & 101 \\
\hline Specialists' Degree & 12 \\
\hline Master's Degree & 134 \\
\hline Doctoral Degree & 4 \\
\hline Professional Degree (JD, MD) & 2 \\
\hline
\end{tabular}


The Effectiveness of K-12 Principal's Digital Leadership in Supporting and Promoting Communication and Collaboration Regarding CCSS Implementation

Table 5. Teaching grade

\begin{tabular}{|l|l|}
\hline Teaching Grade & Teacher Number \\
\hline Kindergarten & 30 \\
\hline Elementary grade: $1-4$ & 54 \\
\hline Elementary grade: $5-8$ & 85 \\
\hline High school: $9-12$ & 86 \\
\hline
\end{tabular}

Table 6. Descriptive statistics of each scale

\begin{tabular}{|l|c|c|c|}
\hline Scale & Mean & SD & N \\
\hline Visionary Leadership & 3.55 & 0.91 & 255 \\
\hline Digital Learning Culture & 3.61 & 0.87 & 255 \\
\hline Professional Development & 3.97 & 0.81 & 256 \\
\hline Systemic Improvement & 3.56 & 0.85 & 255 \\
\hline Digital Citizenship & 3.92 & 0.79 & 254 \\
\hline
\end{tabular}

\subsection{Visionary Leadership}

Statement Q5, Q6, Q7, and Q8 describe digital leadership strategies from visionary leadership perspective. Table 7 contains the descriptive statistics of each statement in visionary leadership. Among the four statements, the Q6 statement has the highest rating. Q7 and Q8 have same lowest rating. Figure 1 shows teachers' agreement proportion of each statement. Q6 has the highest percent of agreement, which takes $72 \%$ of total responses. Q7 has the least proportion of agreement, which accounts for $52 \%$. The proportion of Q6 is 20\% higher than Q7.

Table 7. Descriptive statistics of visionary leadership

\begin{tabular}{|l|c|c|c|}
\hline Item & Mean & SD & N \\
\hline Q5 & 3.65 & 1.15 & 251 \\
\hline Q6 & 3.82 & 1.03 & 253 \\
\hline Q7 & 3.37 & 1.17 & 250 \\
\hline Q8 & 3.37 & 1.30 & 252 \\
\hline
\end{tabular}

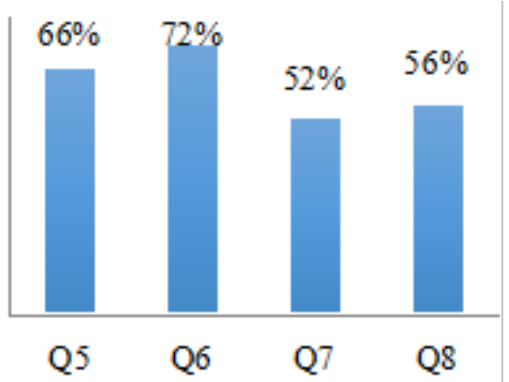

Figure 1. Proportion of people agreed with the visionary leadership questions. 


\subsection{Digital learning culture}

Statement Q9, Q10, Q11, and Q12 describe digital leadership strategies from digital learning culture perspective.Table 8 contains the descriptive statistics of each statement in digital learning culture scale. Among the four statements, statement Q9 has the lowest rating. Q10 has the same low rating as Q11. Figure 2 shows the agreement proportion of each statement in digital learning culture. Q10 and Q11 have the highest agreement proportion, which take $68 \%$ of total responses. Q9 has the least agreement proportion, which accounts for $57 \%$. The agreement proportion of Q10 is almost 10\% higher than Q9.

Table 8. Descriptive statistics of digital learning culture

\begin{tabular}{|l|c|c|c|}
\hline Item & Mean & SD & N \\
\hline Q9 & 3.40 & 1.20 & 253 \\
\hline Q10 & 3.63 & 1.10 & 252 \\
\hline Q11 & 3.71 & 1.13 & 253 \\
\hline Q12 & 3.71 & 1.18 & 252 \\
\hline
\end{tabular}

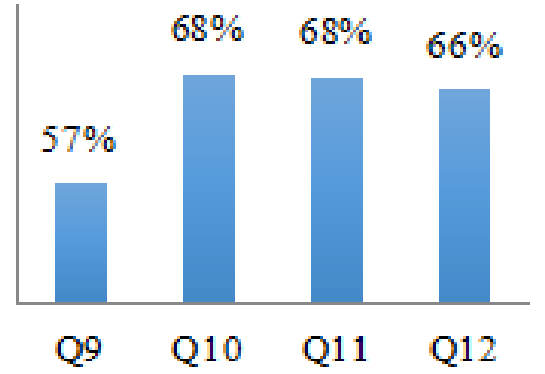

Figure 2. Proportion of people agreed with the digital learning culture questions.

\subsection{Professional Development}

Statement Q13, Q14, Q15, and Q16 describe digital leadership strategies from professional development perspective. Table 9 contains the descriptive statistics of each statement in professional development scale. Among the four statements in the professional development scale, Q16 has the lowest rating and Q15 has the highest rating. Figure 3 shows the agreement proportion of each item in professional development. Q15 has the highest agreement proportion, in which $90 \%$ people agreed with this item. Q16 has the least agreement proportion, which accounts for $68 \%$. The highest proportion of agreement is more than $30 \%$ higher than the lowest proportion of agreement. 
The Effectiveness of K-12 Principal's Digital Leadership in Supporting and Promoting Communication and Collaboration Regarding CCSS Implementation

Table 9. Descriptive statistics of professional development

\begin{tabular}{|l|c|c|c|}
\hline Item & Mean & SD & N \\
\hline Q13 & 3.95 & 1.06 & 252 \\
\hline Q14 & 4.11 & 0.95 & 252 \\
\hline Q15 & 4.23 & 0.96 & 254 \\
\hline Q16 & 3.58 & 1.10 & 253 \\
\hline
\end{tabular}

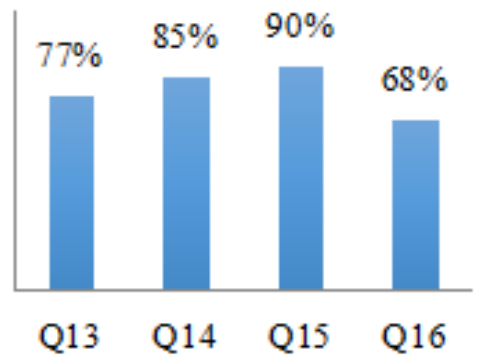

Figure 3. Proportion of people agreed with the professional development questions.

\subsection{Systemic Improvement}

Statement Q17, Q18, Q19, and Q20 describe digital leadership strategies from systemic improvement perspective.Table 10 contains the descriptive statistics of each statement in systemic improvement scale. Among the four statements in the systemic improvement scale, statement Q19 has the lowest rating and Q18 has the highest rating. Figure 3 shows the agreement proportion of each item in systemic improvement. Q18 has the highest proportion of agreement, in which $78 \%$ people agree with this statement. Q19 has the least proportion of agreement, which accounts for $37 \%$. In other words, more than

Table 10. Descriptive statistics of systemic improvement

\begin{tabular}{|l|c|c|c|}
\hline Item & Mean & SD & N \\
\hline Q17 & 3.67 & 1.04 & 248 \\
\hline Q18 & 3.88 & 1.06 & 253 \\
\hline Q19 & 3.06 & 1.13 & 251 \\
\hline 210 & 3.63 & 1.09 & 252 \\
\hline
\end{tabular}

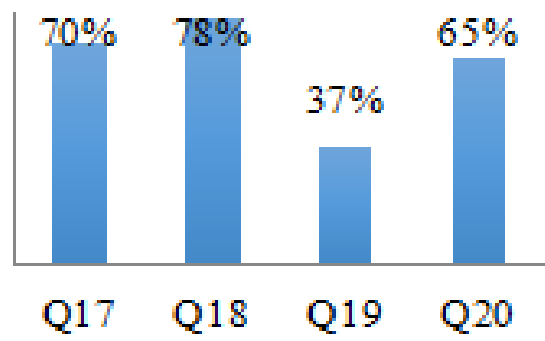

Figure 4. Proportion of people agreed with the systemic improvement questions. 
half of the participants do not agree with Q19. The highest proportion of agreement is $40 \%$ higher than the lowest proportion of agreement.

\subsection{Digital Citizenship}

Statement Q21, Q22, Q23, and Q24 describe digital leadership strategies from digital citizenship perspective.Table 11 contains the descriptive statistics of each statement in digital citizenship scale. Among the four statements in the digital citizenship scale, Q24 has the lowest rating and Q23 has the highest rating. Figure 5 shows the agreement proportion of each statement in digital citizenship. Q23 has the highest agreement proportion, which accounts for $84 \%$ agreement with this statement. Q24 has the least agreement proportion, which accounts for $69 \%$ agreement with this item. The highest agreement proportion is $15 \%$ higher than the lowest proportion of agreement.

Table 11. Descriptive statistics of digital citizenship

\begin{tabular}{|l|c|c|c|}
\hline Item & Mean & SD & N \\
\hline Q21 & 3.80 & 1.02 & 249 \\
\hline Q22 & 4.06 & 1.03 & 250 \\
\hline Q23 & 4.12 & 0.94 & 251 \\
\hline Q24 & 3.74 & 1.08 & 251 \\
\hline
\end{tabular}

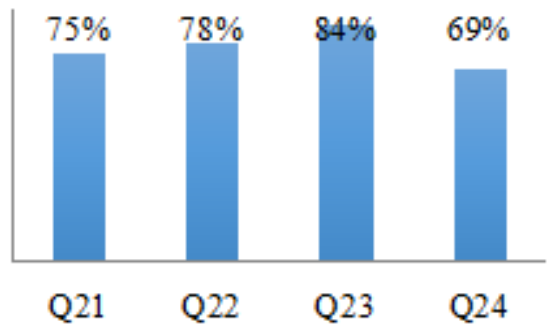

Figure 5. Proportion of people agreed with the digital citizenship questions.

Overall, Q23 has the highest rating, and Q19 is the lowest rating statement. In visionary leadership, Q6 has the highest rating, while Q8 has the lowest rating. In digital learning culture, Q12 has the highest rating, and Q9 has the lowest rating. In professional development, Q15 has the highest rating, while Q16 has the lowest rating. In digital learning culture, Q18 has the highest rating, and Q19 has the lowest rating. In digital learning culture, Q23 has the highest rating, and Q24 has the lowest rating.

\subsection{Demographic Impact}

The last research question focuses on the impact of demographics on each scale of digital leadership. Demographic information included teachers' gender, age, education background, and the grade teachers teach. Results show that there is no significant 
The Effectiveness of K-12 Principal's Digital Leadership in Supporting and Promoting Communication and Collaboration Regarding CCSS Implementation

difference in digital leadership based on teachers' gender $(p>0.05)$. There is significant difference in age $(F(5,247)=3.54, p<0.05)$. Teachers' age has impact on effectiveness of digital citizenship $(F(4,248)=3.68, p<0.05)$. There is no significant difference in digital leadership based on teachers' education background $(p>0.05)$. There is significant difference in teaching grade $(F(5,246)=4.33$, $p<0.05)$. Teaching grade affect effectiveness of visionary leadership $(F(3,248)=3.68$, $p<0.05)$ and professional development $(F(3$, $248)=2.95, p<0.05)$.

Tukey's HSD post-hoc tests were conducted to follow up the significant finding. Results show that, in digital citizenship, 2025 years old teachers are different from $26-$ 34 years old teachers $(p<0.05) .20-25$ years old teachers are different from 55-64 years old teachers $(p<0.05)$. In visionary leadership, kindergarten teachers are different from grade 1-4 teachers $(p<0.05)$ and high school teachers $(p<0.05)$. In professional development, kindergarten teachers are different from grade 1-4 teachers $(p<0.05)$ and high school teachers $(p<0.05)$.

\section{Discussion}

Research Question 1: Are digital leadership strategies effective in supporting and promoting communication and collaboration regarding CCSS implementation in Mississippi?

Results showed that principals' digital leadership strategies are effective in supporting and promoting communication and collaboration regarding CCSS implementation in Mississippi. Specifically, principals are most effective in supporting professional development and digital citizenship than visionary leadership, digital culture learning, and systemic improvement. Analysis of survey items shows that principals need to improve strategies of supporting technology integration demonstration and access to digital resources. With regard to visionary leadership, digital age culture learning, and systemic improvement, more efforts are needed on improving in technology demonstrations related to instructional strategies, collaborating with technology representatives, and having more two-way communication and collaboration with teachers through web 2.0 tools such as Google Drive.

Research Question 2: To what extent are digital leadership strategies effective in supporting and promoting communication and collaboration regarding CCSS implementation in Mississippi?

First, although principals are effective in professional development and digital citizenship, some strategies in professional development and digital citizenship still need to be improved.

In terms of professional development, strategy of modeling effective technology use during meetings with teachers is the least effective strategy compared with other strategies in professional development. The low technology promotion shows that the understanding of professional development in digital leadership is still limited to providing training regarding the digital resources. Communication and collaboration regarding professional development between the principals and the teachers are constrained by traditional strategies of professional development. Although social media is identified as a new way of conducting professional development, principals acknowledge that they are just starting to use social media and the teachers still need long time to become comfortable with professional development in social media. Conclusively, 
more support is required in promoting effective technology use among teachers.

Teachers' average agreement proportion of professional development items is above $80 \%$, which indicates that the principals fully understand the requirements of professional development and place their effort in supporting teachers' professional development. Almost 90\% teachers show their agreements for holding group meetings. It indicates that group meeting is the most effective strategy for supporting professional development. Finding also demonstrates the importance of establishing a learning community for teachers' professional development. Group meeting plays an essential role in supporting meaningful learning (Vygotsky, 1978). Teachers learn from each other by sharing experiences and gaining support from the community. Individual knowledge is re-shared and improved during the interaction process.

Findings of professional development are also consistent with previous study (Lecklider et al., 2009), which demonstrate that professional development is the first priority for principals. All statements in professional development are rated above $75 \%$, which indicate that principals are successful in supporting the teachers' professional development. Principals should continue their strategies in professional development. For future improvement, the principals are suggested to improve technology modeling during the meetings with teachers.

With regard to digital citizenship, strategy of modeling effective technology use during meetings with teachers is the least effective strategy compared with other strategies in professional development. The lack of support in access to digital resources may cause teachers' inconvenience of implementing CCSS. Schools have website filters that protect teachers and students from inappropriate information on Internet. However, the website filter also blocks some instructional resources from being used in classrooms. Results also indicate that most support of digital citizenship come from the school districts. Although schools have a few digital citizenship supports, more effort should be placed on improving digital citizenship. Effective digital citizenship support does not only mean following copyright rules and laws, but also helping students and teachers improving digital learning environment. Principals should take full use of instructional designers from school districts and if possible, hire schools' own instructional designers to ensure successful digital citizenship support.

Findings of digital citizenship in this study are consistent with the study conducted by Metcalf and LaFrance (2013) but contradict with the study conducted by Richardson et al. (2012). Metcalf and LaFrance (2013) measured technology leadership preparedness from principals' perceptions and results showed that digital citizenship was the more prepared indicator. However, Richardson et al. (2012) reviewed the literature related to digital leadership and reported that digital citizenship was paid less attention and more studied were needed for digital citizenship. Findings from this study show similar conclusion as the study conducted by Metcalf and LaFrance (2013) that strategies in digital citizenship are the most effective strategies of digital leadership.

This study shows visionary leadership strategies are the least effective strategies. Findings of visionary leadership are evidently consistent with previous studies (Banoglu, 2011; Metcalf \& LaFrance, 2013). In the study conducted by Banoglu (2011), results show that visionary leadership is the lowest value compared with other indicators. Metcalf and 
The Effectiveness of K-12 Principal's Digital Leadership in Supporting and Promoting

Communication and Collaboration Regarding CCSS Implementation

LaFrance (2013) have same conclusions in their study that visionary leadership is the least prepared indicator. Principals need to improve their strategies related to technology modeling, which would impact instructional strategies for the teachers (Q7). In addition, the agreement proportion of social media utilization is similar to technology modeling. Only half of the teachers agreed with the visionary leadership strategies related to technology modeling and social media utilization. One explanation may be the different perspective of how technology integration should be demonstrated. The principals understand technology demonstration as digitally presentations. However, the teachers understand technology demonstration as delivering information with purpose of introducing instructional methods. Therefore, principals should continue developing and improving shared understanding of visionary leadership. In addition, more efforts are required for supporting technology modeling and social media utilization in visionary leadership.

Strategies of digital learning culture are more effective than strategies of visionary leadership and digital citizenship but less effective than professional development and systemic improvement. In digital age learning culture, strategy of having technology representatives come to campus (Q9) is the least effective strategy compared with other strategies in digital age learning culture. Only $57 \%$ teachers agreed with this statement. Results indicate that support from technology representatives are not enough. One of the reasons of this inadequate support from technology representatives might be the technology representatives' main purpose is to sell and maintain devices rather than providing instructional technology support for teachers. Besides, those technology representatives may not have enough instructional design knowledge and skills to help with teachers' instructional use of the devices.

In addition, the total agreement proportion of the three statements except Q9 is almost $68 \%$. It indicates that two-thirds of the teachers were using digital tools for communication and collaboration regarding CCSS. In other words, there are one-third teachers do not use technology for communication and collaboration at all. However, based on the data in this study, it is difficult to conclude why those one-third teachers do not use technology for communication and collaboration at all. Thus, investigating why those one-third teachers do not use technology and how to support those teachers with their communication and collaboration regarding CCSS can benefit the principal and policy makers.

Findings of digital learning culture are new findings that have not been addressed in previous studies. Although Lecklider et al. (2009) have provided an example of creating digital learning culture, discussion of effectiveness of strategies in digital learning culture were not included in this study. This study fills in this gap by providing the evidence of the effectiveness of strategies in digital learning culture. In addition, this study demonstrates that teachers' gender, age, educational background, and teaching grade do not have impact on the principals' strategies in digital learning culture. Therefore, the principals are suggested to plan digital learning culture for all the teachers regardless of their demographics.

In systemic improvement, strategy of asking teachers questions through digital technologies, such as Google Docs, is the least effective strategy compared with other strategies in systemic improvement. Particularly, more than half participants disagree with this strategy. More than half 
teachers do not agree with this statement, which indicates that there is something wrong with the utilization of Google Docs. One explanation of the low rate might be inappropriate ways of using Google Docs. Teachers might not be comfortable in discussing lessons with principals through Google Docs. Communication and collaboration via Google Docs might occur a lot between teachers instead of between teachers and principals. However, other three statements, which are one-way communication methods, get high rates. Results indicate that principals use technology as tool of sharing information rather than a way of communication and collaboration. Technology has rarely been used to communicate and collaborate with teachers. There is no twoway communication in scale of systemic improvement.

Findings of systemic improvement are consistent with the study conducted by Richardson et al. (2012), which show that systemic improvement is paid less attention and is as less effective as visionary leadership. One possible explanation is principals' incorrect understanding of systemic improvement. Therefore, principals also need help with strategies of systemic improvement. Thus, principals and school districts should pay more attention to systemic improvement, especially the utilization of Google Docs. Further research is required to investigate the strategies that principals can use to improve the effectiveness of strategies in systemic improvement.

Research Question 3: Do demographics make difference in any of the scales of digital leadership?

Results indicate that demographics did make a difference in the scales of digital leadership. Specifically, teachers' age had impact on strategies in digital citizenship. Teachers' teaching grade had effect on strategies related to visionary leadership and professional development.

Teachers' age had impact on the effectiveness of principals' strategies in digital citizenship. Teachers between 20 years old and 25 years old were different from teachers between 55 years old and 64 years old in strategies in digital citizenship. Teachers between 20 years old and 25 years old were different from teachers between 26 years old and 34 years old in strategies in digital citizenship. Thus, principals needed to consider the different age groups when planning digital citizenship strategies.

Findings also showed that teachers' teaching grade had impact on principals' strategies in professional development. Kindergarten teachers were different from grade 1-4 teachers and high school teachers. Therefore, principals should make different strategies for kindergarten teachers, grade 1-4 teachers, and high school teachers.

There was significant difference between kindergarten teachers and 1-4 grade teachers. High school teachers were also different from kindergarten teachers regarding visionary leadership strategies. Those differences indicated that principals should consider the teaching grade in visionary leadership strategies. For instance, principals were highly recommended to make different visionary leadership for different grade teachers.

In summary, different strategies are required for different age teachers and different grade teachers. Demographics do make differences in digital leadership. Effectiveness of visionary leadership and professional development are affected by teaching grade. 
The Effectiveness of K-12 Principal's Digital Leadership in Supporting and Promoting

Communication and Collaboration Regarding CCSS Implementation

Effectiveness of digital citizenship is impacted by teacher's age.

\section{Implications}

Findings of this study have provided empirical evidence of effectiveness of digital leadership in supporting communication and collaboration regarding CCSS. Besides school principals, other school leaders and educators who are interested in CCSS implementation could also benefit from this study.

This study indicates that the digital leadership training of principals should focus on visionary leadership, digital age learning culture, and systemic improvement. Lowest rating of visionary leadership and systemic improvement shows that principals should be trained to improve the skills of creating shared visions of integrating technology into schools and using digital data to support schools' continuous improvement. Therefore, district leaders need to focus on how to improve principals' knowledge and skills of visionary leadership, digital age learning culture, and systemic improvement. In addition, school districts can refer to the results of this study to improve specific element of digital leadership, such as systemic improvement. For instance, encouraging and demonstrating how Google Docs can enhance the interactions with teachers is a good strategy of improving effectiveness of systemic improvement. Principals can share schools' documents with teachers through Google Docs. Another good strategy to improve systemic improve is to collect information from teachers through Google Docs. Teachers have to use Google Docs to complete their work. Thus, teachers can get experience of using Google Docs to communicate and collaborate with others during the process of interacting with principals. Principals are also recommended to keep continuous support in professional development and digital citizenship. Particularly, although strategies of digital citizenship were effective based on the findings, more effort were suggested on digital citizenship. In addition, most strategies of digital citizenship came from school districts. However, each school had different situation. Therefore, principals need to develop their own strategies of digital citizenship according to their schools' need.

\section{Conclusion}

This study investigated effectiveness of digital leadership in supporting and promoting communication and collaboration regarding CCSS in K-12 schools. 254 public school teachers from five school districts in Mississippi were surveyed and results showed that principals were most effective in digital strategies related to professional development and digital citizenship. Teachers' age and the grades they teach have impact on effectiveness of principals' digital leadership strategies. Principals and administrators are recommended to keep current digital strategies related to professional development and digital citizenship and switch focus of digital leadership strategies to visionary leadership, digital age learning culture, and systemic improvement. It is hoped that findings of this study can be used as guidelines to help principals and administrators improve digital leadership practice. 


\section{References}

Afshari, M., Bakar, K. A., Luan, W. S., \& Siraj, S. (2012). Factors affecting the transformational leadership role of principals in implementing ICT in schools. The Turkish Online Journal of Educational Technology, 11(4), 164-176.

Arokiasamy, A. R. A., Abdullah, A. G. K., \& Ismail, A. B. (2014). Correlation between cultural perceptions leadership style and ICT usage school principals in Malaysia. The Turkish Online Journal of Educational Technology, 13(3), 27-40.

Banoglu, K. (2011). School principals' technology leadership competency and technology coordinatiorship. Educational Sciences: Theory and Practice, 11(1), 208-213.

Blase, J., \& Blase, J. (2000). Effective instructional leadership: Teachers' perspectives on how principals promote teaching and learning in schools. Journal of Educational Administration, 38(2), 130-141.

Brandt, B. (2012). Leading change: Transitioning to the common core. School Business Affairs, 78(6), 17-19.

Burton, B. (2014). How Teachers use Technology to Meet English Language Arts Common Core State Standards. In M. Searson \& M. Ochoa (Eds.), Proceedings of Society for Information Technology \& Teacher Education International Conference (pp. 2739-2744). Chesapeake, VA: Association for the Advancement of Computing in Education (AACE).

Butler, K. (2010). A small district's big innovator. District Administration, 2(2), 41-44.

Cakir, R. (2009). Technology integration and technology leadership in schools as learning organizations. Turkish Online Journal of Educational Technology, 11(4), 273-282.

Cheng, A. (2012). Teachers'perceptions of the common core state standards. (Unpublished master's thesis). Biola University, La Mirada, California.

Cogan, L., Schimidt, W., \& Houang, R. (2013). Implementing the common core state standards for mathematics: What parents know and support. The Education Policy Center at Michigan State, 12(3), 108.

Creighton, T. (2003). The principal as technology leader. Thousand Oaks, CA: Sage Publications.

Curnyn, M. A. (2013). Technology leadership conditions among Nebraska school principals (Doctoral dissertation). Retrieved from ProQuest Dissertations and Theses. (Accession Order No. AAT 3607695)

Dessoff, A. (2010). Reaching digital natives on their terms. District Administration, 46(4), 36-38.

Dickerson, J., Winslow, J., Lee, C.Y., \& Geer, G. (2011). iPrincipals: School administrator iPad utilization - Part 1. In M. Koehler \& P. Mishra (Ed.), Society for Information Technology \& Teacher Education International Conference (pp. 2952-2953), Chesapeake, VA: Association for the Advancement of Computing in Education (AACE).

Darrow, R. (2010). The bottom line: Funding online courses. School Administrator, 67(4), 26-30.

Fowler. F. J. (2014). Survey Research Methods (5th ed.). Thousand Oaks, CA: Sage Publications.

Gallia, T. (2012). A quantitative content analysis of the common core state standards compared to Missouri's gradelevel expectations using the revised Bloom's taxonomy framework (Doctoral dissertation). Retrieved from ProQuest Dissertations and Theses. (Accession Order No. AAT 3552222)

Garcia, A., \& Abrego, C. (2014). Vital skills of elementary principal as a technology leader. Journal of Organizational 
The Effectiveness of K-12 Principal's Digital Leadership in Supporting and Promoting Communication and Collaboration Regarding CCSS Implementation

Learning and Leadership, 12(1), 12-25.

Graham, M. J. (2013). Google apps meets common core. London, UK: Sage Publications.

Hipsher, C. A. (2014). Educators' Perceptions Regarding Common Core State Standards and Professional Development (Unpublished doctoral dissertation). Liberty University, Lynchburg, Virginia.

Holliday, T., \& Smith, F. C. (2012). Leading common core implementation. Principal, $1(1), 12-15$.

International Society for Technology in Education (ISTE). (2002). National educational technology standards (NETS) and performance indicators for administrators. Retrieved on December 19, 2014, from http://www. iste.org/Content/NavigationMenu/NETS/ ForAdministrators/2002Standards/NETS for_Administrators_2002_standards.htm.

ISTE standards for Administrators (ISTE-A). (2009). National educational technology standards for administrators. Retrieved from http://www.iste.org/Libraries/PDFs/ NETS_for_Administrators_2009_EN.sflb. ash $\mathrm{x}$.

Jameson, J. (2013). E-leadership in higher education: The fifth "age" of educational technology research. British Journal of Educational Technology, 44(6), 889-915.

Kearsley, G., \& Lynch, W. (1992). Educational leadership in the age of technology: The new skills. Journal of Research on Computing in Education, 25(1), 50-60.

Kober, N. \& Renter, D. (2012). State education agency funding and staffing in the education reform era. Washington, DC: The Center for Education Policy. Retrieved from http://www.cep-dc.org/ displayDocument.cfm?DocumentID=396

Larson, L., Miller, T., \& Ribble, M. (2009). Five considerations for digital age leaders: What principals and district administrators need to know about tech integration today. Learning \& Leading with Technology,
37(4), 12-15.

Lecklider, D., Clausen, J. M., \& Britten, J. S. (2009). Principals priority for technology as an indicator of observed used in schools. Journal of Scholarship and Practice, 5(4), 27-33.

Marks, H. M. (2003). Principal leadership and school performance: An integration of transformational and instructional leadership. Educational Administration Quarterly, 39(3), 370-397.

McCombs, B. (2010). Culture of collaboration. Learning \& Leading with Technology, 38(3), 10-13.

McLaughlin, M., \& Overturf, B. J. (2012). The common core: Teaching K-5 students to meet the reading standards. Newark: International Reading Association.

McLaughlin, M., \& Overturf, B. J. (2013). The common core: Teaching students in grades 6-12 to meet the reading standards. Newark, NJ: International Reading Association.

McLoughlin, C., \& Lee, M. J. W. (2007). Social software and participatory learning: pedagogical choices with technology affordances in the Web 2.0 era. Proceedings from ICT: Providing choices for learners and learning, Singapore: Centre for Educational Development, Nanyang Technological University.

Metcalf, W., \& LaFrance, J. (2013). Technology leadership preparedness: Principals' perceptions. Journal of Research in Education, 23(1), 58-76.

Neuman, S. B., \& Gambrell, L. B. (Eds.) (2013) Quality reading instruction in the age of common core standards. Newark, NJ: International Reading Association.

Ribble, M., \& Miller, T. N. (2013). Educational leadership in an online world: Connecting students to technology responsibility, safely, and ethically. Journal of Asynchronous Learning Networks, 17(1), 137-145.

Richardson, J. W., Flora, K., \& Bathon, J. 
(2013). Fostering a school technology vision in school leader. International Journal of Educational Leadership Preparation, 8(1), 144-160.

Ritzhaupt, A. D., Hohlfeld, T. N., Barron, A. E., \& Kemker, K. (2008). Trends in technology planning and funding in Florida K-12 public schools. International Journal of Education Policy \& Leadership, 3(8), 1-17.

Rivard, L. R. (2010). Enhancing education through technology: Principal leadership for technology integration in schools (Doctoral dissertation). Retrieved from ProQuest Dissertations and Theses. (Accession Order No. AAT 3427277)

Robertson, C. (2013). Using a Cloud-based Computing Environment to Support Teacher Training on Common Core Implementation. TechTrends, 57(6), 5760.

Rovai, A. P., Baker, J. D., \& Ponton, M. K. (2014). Social science research design and statistics: A practioner's guide to research methods and IBM spss analysis (2nd, ed.). Chesapeake, VA: Watertree Press.

Royer, R., \& Richards, P. (2013). Multimedia Fosters Literacy Achievement in Common Core Standards. In . Jan Herrington et al. (Eds.), Proceedings of World Conference on Educational Multimedia, Hypermedia and Telecommunications (pp. 2265-2270). Chesapeake, VA: Association for the Advancement of Computing in Education (AACE).

Stegmaier, M. R. (2013). The role of the school librarian as a collaborative partner in relationship to the common core state standards. (Unpublished master's thesis). University of Central Missouri, Warrensburg, Missouri.

Underwood, C. (2014). Principal Perceptions of Common Core State Standards and The Implications for Teacher Evaluation (Unpublished doctoral dissertation). California State University, California.
Vasinda, S. (2014). Finding the common ground: A comparison of writing expectations and outcomes between the Texas essential knowledge and skills and the common core state standards. Texas Journal of Literacy Education, 2(1), 6986.

Vygotsky, L. S. (1978). Mind in society: The development of higher psychological process. Cambridge, MA: Harvard University Press.

Wahlstrom, K. L., \& Louis, K. S. (2009). How teachers experience principal leadership: The roles of professional community, trust, efficacy, and shared responsibility. Educational Administration Quarterly, 44(4), 458-495.

Wang, C. (2010). Technology leadership among school principals: A technologycoordinator's perspective. Asian Social Science, 6(1), 51-54.

Winslow, J., Dickerson, J., Lee, C., \& Geer, G. (2012). Mobile technologies: Tools for organizational learning and management in schools. International Education Studies, 5(4), 188-195.

Yang, H. H., \& Chen, P. (2010). Exploring teachers' beliefs about digital citizenship and responsibility. In K. Elleithy, T. Sobh, M. Iskander, V. Kapila, \& M. A. Karim (Ed.), Technological Developments in Networking, Education and Automation (pp. 49-54). New York, NY: Springer.

Yim, S., Warschauer, M., Zheng, B., \& Lawrence, J. (2014). Cloud-based collaborative writing and the common core standards. Journal of Adolescent \& Adult Literacy, 58(3), 243-254.

Zhang, S. (2014). New teachers' implementation of the common core standards. Action in Teacher Education, 36(5), 465-479.

Zhong, L. (2017). Indicators of digital leadership in the context of K-12 education. Journal of Educational Technology Development and Exchange, 10(1), 27-40. 


\section{Contact the Author}

\section{Lin Zhong}

Southern Illinois University

Carbondale, USA

Email:

\section{Appendix A. Survey for K-12 Teachers}

How do you rate your experience with principal in supporting communication and collaboration regarding CCRS implementation? Please select the appropriate rate.

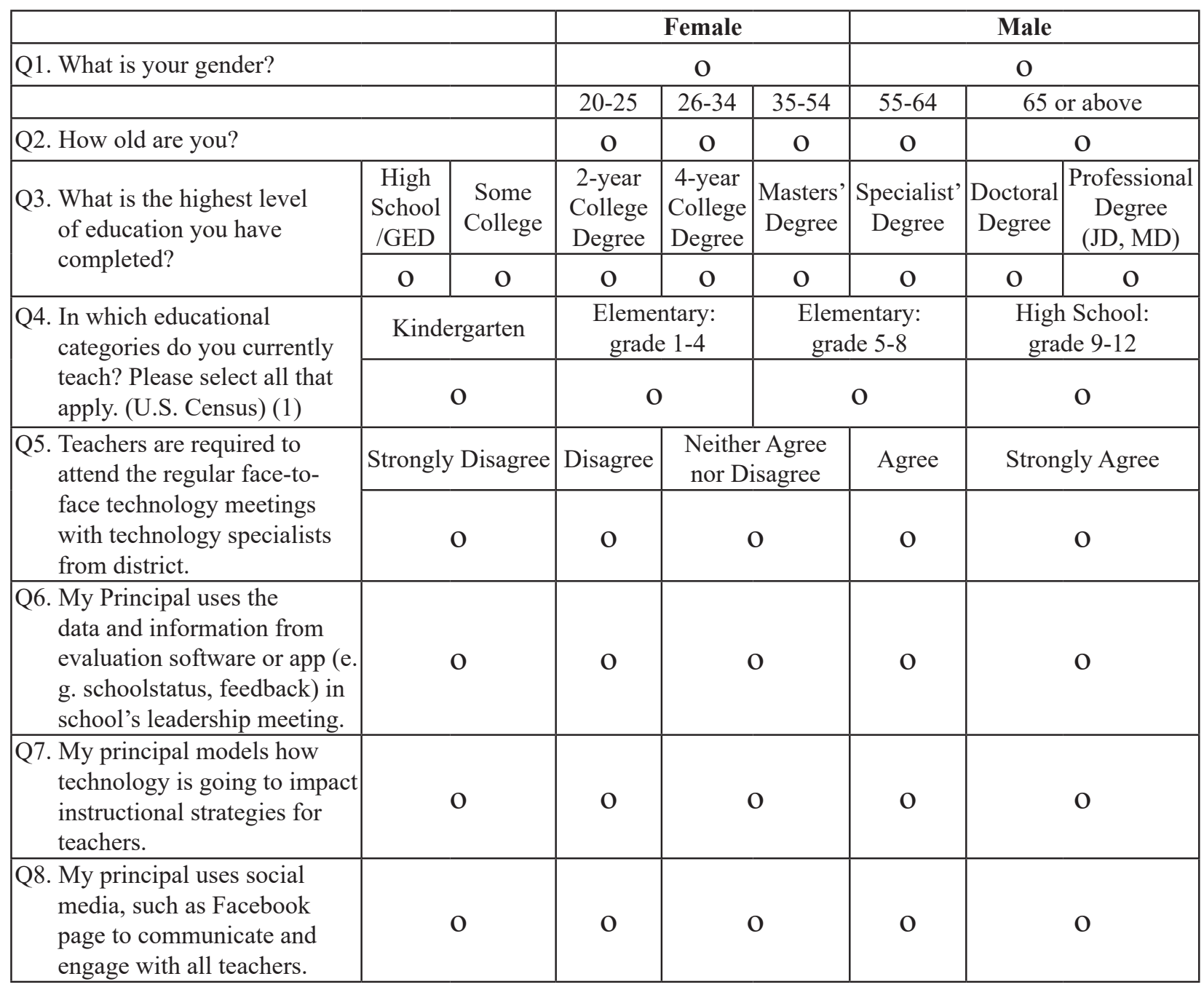


How do you rate your experience with principal in supporting communication and collaboration regarding CCRS implementation? Please select the appropriate rate.

\begin{tabular}{|c|c|c|c|c|c|}
\hline \multirow{2}{*}{$\begin{array}{l}\text { Q9. Technology representatives } \\
\text { regularly come to the campus } \\
\text { and provide hands on support, } \\
\text { including technology updates } \\
\text { or new tools demonstration. }\end{array}$} & Strongly Disagree & Disagree & $\begin{array}{c}\text { Neither Agree } \\
\text { nor Disagree }\end{array}$ & Agree & Strongly Agree \\
\hline & $\mathrm{O}$ & $\mathrm{O}$ & $\mathrm{O}$ & $\mathrm{O}$ & $\mathrm{O}$ \\
\hline $\begin{array}{l}\text { Q10. My principal will } \\
\text { help and support good } \\
\text { communication with teachers } \\
\text { (e. g., explaining the ways } \\
\text { of communication, how to } \\
\text { use some communication } \\
\text { tools, explains the value of } \\
\text { the communication tools, and } \\
\text { constantly show the teachers } \\
\text { why digital communications } \\
\text { tools are important). } \\
\end{array}$ & $\mathrm{O}$ & $\mathrm{O}$ & $\mathrm{O}$ & $\mathrm{O}$ & $\mathrm{O}$ \\
\hline $\begin{array}{l}\text { Q11. Teachers will train each } \\
\text { other, model lessons, and } \\
\text { share training materials } \\
\text { with other teachers through } \\
\text { Google Drive. }\end{array}$ & $\mathrm{O}$ & $\mathrm{O}$ & $\mathrm{O}$ & $\mathrm{O}$ & $\mathrm{O}$ \\
\hline $\begin{array}{l}\text { Q12. School is trying to } \\
\text { encourage teachers to put as } \\
\text { much information as they } \\
\text { can on school website so } \\
\text { that students can pull out the } \\
\text { book online or see the notes } \\
\text { that might be helpful when } \\
\text { they are at home. }\end{array}$ & $\mathrm{O}$ & $\mathrm{O}$ & $\mathrm{O}$ & $\mathrm{O}$ & $\mathrm{O}$ \\
\hline $\begin{array}{l}\text { Q13. Teachers are required } \\
\text { to attend face-to-face } \\
\text { professional development } \\
\text { technology meetings. } \\
\end{array}$ & $\mathrm{O}$ & $\mathrm{O}$ & $\mathrm{O}$ & $\mathrm{O}$ & $\mathrm{O}$ \\
\hline $\begin{array}{c}\text { Q14. Digital tools are provided } \\
\text { for teachers to communicate } \\
\text { with principals. (e.g., SAMS, } \\
\text { Remind.com, Blackboard, } \\
\text { Google Drive, School Wires) }\end{array}$ & $\mathrm{O}$ & $\mathrm{O}$ & $\mathrm{O}$ & $\mathrm{O}$ & $\mathrm{O}$ \\
\hline $\begin{array}{l}\text { Q15. Teachers meet in grade level } \\
\text { meetings to share ideas for } \\
\text { their lessons. }\end{array}$ & $\mathrm{O}$ & $\mathrm{O}$ & $\mathrm{O}$ & $\mathrm{O}$ & $\mathrm{O}$ \\
\hline
\end{tabular}


The Effectiveness of K-12 Principal's Digital Leadership in Supporting and Promoting Communication and Collaboration Regarding CCSS Implementation

How do you rate your experience with principal in supporting communication and collaboration regarding CCRS implementation? Please select the appropriate rate.

\begin{tabular}{|c|c|c|c|c|c|}
\hline \multirow{2}{*}{$\begin{array}{l}\text { Q16. My principal models } \\
\text { effective technology use } \\
\text { during meetings with } \\
\text { teachers. }\end{array}$} & Strongly Disagree & Disagree & $\begin{array}{c}\text { Neither Agree } \\
\text { nor Disagree }\end{array}$ & Agree & Strongly Agree \\
\hline & $\mathrm{O}$ & $\mathrm{O}$ & $\mathrm{O}$ & $\mathrm{O}$ & $\mathrm{O}$ \\
\hline $\begin{array}{l}\text { Q17. My principal interprets the } \\
\text { evaluation results to teachers } \\
\text { via e-mail. }\end{array}$ & $\mathrm{O}$ & $\mathrm{O}$ & $\mathrm{O}$ & $\mathrm{O}$ & $\mathrm{O}$ \\
\hline $\begin{array}{l}\text { Q18. My principal uses digital } \\
\text { tools (e. g., School Status, } \\
\text { Feedback) to evaluate } \\
\text { teaching (e.g. leave } \\
\text { comments after observation). }\end{array}$ & $\mathrm{O}$ & $\mathrm{O}$ & $\mathrm{O}$ & $\mathrm{O}$ & $\mathrm{O}$ \\
\hline $\begin{array}{l}\text { Q19. My principal asks questions } \\
\text { about the lessons through } \\
\text { Google Docs. }\end{array}$ & $\mathrm{O}$ & $\mathrm{O}$ & $\mathrm{O}$ & $\mathrm{O}$ & $\mathrm{O}$ \\
\hline $\begin{array}{l}\text { Q20. My principal uses } \\
\text { technology to share good } \\
\text { examples of teaching with } \\
\text { other teachers. }\end{array}$ & $\mathrm{O}$ & $\mathrm{O}$ & $\mathrm{O}$ & $\mathrm{O}$ & $\mathrm{O}$ \\
\hline $\begin{array}{l}\text { Q21. My principal teaches proper } \\
\text { use of technology. }\end{array}$ & $\mathrm{O}$ & $\mathrm{O}$ & $\mathrm{O}$ & $\mathrm{O}$ & $\mathrm{O}$ \\
\hline $\begin{array}{l}\text { Q22. Teachers get copy of } \\
\text { technology use handbooks at } \\
\text { the beginning of registration. }\end{array}$ & $\mathrm{O}$ & $\mathrm{O}$ & $\mathrm{O}$ & $\mathrm{O}$ & $\mathrm{O}$ \\
\hline $\begin{array}{l}\text { Q23. My school works } \\
\text { with the district to filter } \\
\text { inappropriate websites to } \\
\text { ensure appropriate use of } \\
\text { technology. }\end{array}$ & $\mathrm{O}$ & $\mathrm{O}$ & $\mathrm{O}$ & $\mathrm{O}$ & $\mathrm{O}$ \\
\hline \begin{tabular}{|l} 
Q24. School helps teachers \\
access useful websites that \\
are blocked by the filters.
\end{tabular} & $\mathrm{O}$ & $\mathrm{O}$ & $\mathrm{O}$ & $\mathrm{O}$ & $\mathrm{O}$ \\
\hline
\end{tabular}

